\title{
sciforum
}

Conference Proceedings Paper

\section{Moisture Transport towards Europe and Extreme Precipitation Events}

\author{
Marta Vázquez ${ }^{1,2,3^{*}}$, Fátima Ferreira ${ }^{3}$, Raquel Nieto ${ }^{1}$, Margarida L. R. Liberato ${ }^{2,3}$ and Luis \\ Gimeno $^{1}$ \\ 1 Environmental Physics Laboratory (EPhysLab), CIM-UVIGO, Universidad de Vigo, Ourense 32004, Spain \\ (martavazquez@uvigo.es) \\ 2 Instituto Dom Luiz, Universidade de Lisboa, 1749-016 Lisboa, Portugal \\ 3 Escola de Ciências e Tecnologia, Universidade de Trás-os-Montes e Alto Douro, Vila Real, Portugal \\ * Correspondence: martavazquez@uvigo.es
}

\begin{abstract}
In the last decades an increase in extreme precipitation events was observed all over the world and, specifically, over Europe. The moisture transport from oceans towards the continent is one of the main factors affecting precipitation patterns. Due to the influence of climate change on moisture transport, investigating the changes in moisture transport from the oceanic sources is of especial interest; resulting particularly relevant the association between transport changes and extreme precipitation events. For the European region, two main moisture sources were found to contribute to precipitation, namely the North Atlantic Ocean and the Mediterranean Sea. In this work, the lagrangian particle dispersion model FLEXPART is applied in order to investigate the contribution from these two sources over the region. The moisture contribution is computed taking into account both climatological mean and extreme precipitation events. From these results, a redistribution on the contribution from the sources is observed associated with extreme precipitation events.
\end{abstract}

Keywords: extreme precipitation, moisture transport, global moisture oceanic sources, Europe

\section{Introduction}

On the recent years the precipitation patterns have changed due to the effect of climate change [1]. This change is especially relevant in terms of extreme precipitation events [2]. Several studies have observed an intensification in the occurrence of extreme events over different areas in the world $[2,3]$ and the occurrence is expected to double per degree of temperature increase [4]. Despite several causes can be pointed to influence extreme precipitation patterns, the influence of moisture transport is obvious. The changes observed in the moisture budget over main global moisture sources (such as the North Atlantic Ocean or Mediterranean Sea) [5,6] affect the moisture transport towards continents and, eventually, could affect extreme precipitation patterns [7].

Over Europe, the extreme precipitation events are directly linked with synoptic systems such as extratropical cyclones or atmospheric rivers [8-10]. Most of the cyclones enter the continent form the North Atlantic or the Mediterranean region [9] while ARs have their origin on the transport across the Atlantic [8]. For these reasons, these two sources are expected to be especially relevant on the extreme precipitation events occurring over the region. The importance of these sources over Europe have been previously highlighted by Nieto et al. [11] which attributed to those sources most of the 
moisture contribution in Europe. However, how these sources' contribution affect extreme precipitation was not analyzed in detail until the moment.

In this work the extreme precipitation events over Europe are investigated in terms of moisture transport. Mediterranean Sea and North Atlantic moisture contributions are investigated and compared between mean climatological contribution and extreme precipitation events, at the monthly scale, in order to analyze the importance of these sources over the area.

\section{Experiments}

The present analysis investigates the moisture transport associated with extreme precipitation, from the Mediterranean Sea (MED) and North Atlantic (NATL) moisture sources towards Europe, being the particle dispersion model FLEXPART v 9.0 [12-15] applied for this purpose. The MED and maximum NATL moisture sources areas are presented in Figure 1. The MED source corresponds to the complete basin area and it is constant for every month. However, NATL was monthly defined by Nieto et al. [11] by considering the $50^{\text {th }}$ percentile on the Vertical Integrated Moisture Flux (VIMF) in order to select the most evaporative area over the ocean. The monthly NATL moisture source's extent is presented in Figure S1.

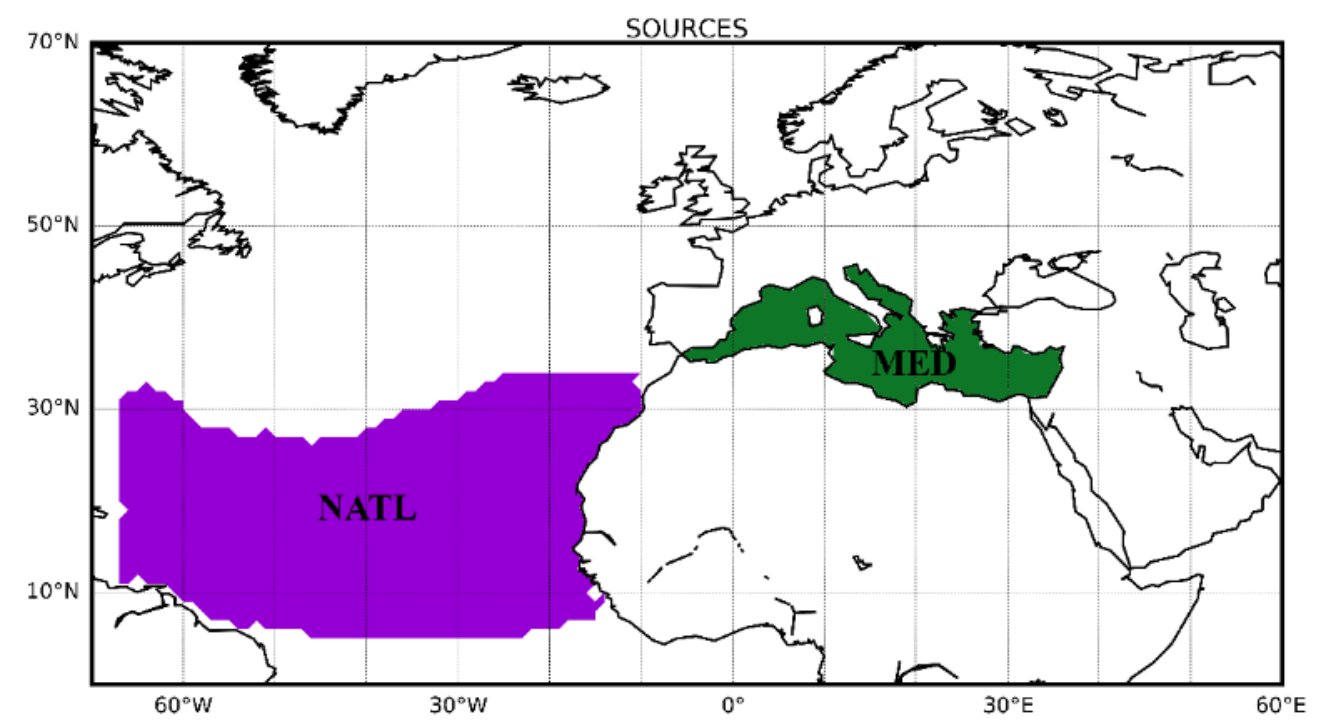

Figure 1. Moisture sources definition according to Nieto et al [11]

The FLEXPART model allows to follow the trajectory of particles from the sources and to analyze the moisture contribution that they produce over specific area. In this study the methodology stablished by Stohl and James [16,17] is applied. An approximate number of 47000 and 10000 particle trajectories are followed from the NATL and MED sources respectively towards continents for every day in the period 1980-2018. The trajectories are followed during 15 days as this is the maximum optimal time of integration for Lagrangian approaches (topt) as defined by Nieto and Gimeno [18].

In order to analyze the moisture variation experienced by the particles along their trajectories, the position (in longitude and latitude) and the specific humidity (q) for every single particle are recorded every $6 \mathrm{~h}$ and the moisture variation (e-p) of the particle computed as $e-p=m \frac{d q}{d t}$ being $\mathrm{m}$ the mass of the particle, $\mathrm{dq}$ the variation in the specific humidity and $\mathrm{dt}$ the $6 \mathrm{~h}$ time step. Over every continental grid area (with $0.5^{\circ} \times 0.5^{\circ}$ resolution) the total moisture budget was computed by considering all the particles that cross the area as follows: 
The 3rd International Electronic Conference on Atmospheric Sciences (ECAS 2020), 16-30 November 2020;

Sciforum Electronic Conference Series, Vol. 3, 2020

$$
E-P=\frac{\sum_{k=1}^{K}(e-p)_{k}}{A}
$$

where $\mathrm{K}$ is the total number of particles crossing the area, $\mathrm{E}$ is evaporation, $\mathrm{P}$ is precipitation and $\mathrm{A}$ is the total grid area. The moisture source is considered to contribute to precipitation if $E-P<0$, so in this study the moisture contribution is defined as $|E-P<0|$ values.

The daily moisture contribution is computed over every grid point by considering the topt. At every grid point the particles that leave the moisture source between 1 to topt days are considered in the $E-P$ computation. From the daily moisture contribution, both the monthly 39 years' climatological averages (1980-2018) and extreme precipitation monthly composites are computed. For the extreme precipitation result, the mean moisture contribution is computed taking into account only those days with precipitation higher than the $95^{\text {th }}$ percentile.

\section{Results}

\subsection{Anomaly in moisture contribution}

In order to analyze the moisture transport towards the European continent from the Mediterranean Sea, the anomalies are computed. Figure 2 represents the anomaly in the moisture contribution for extreme events compared with 1980-2018 climatology for January, April, July and October. The months here analyzed are used to represent the situation for each season while the remaining months are presented as supplementary material.
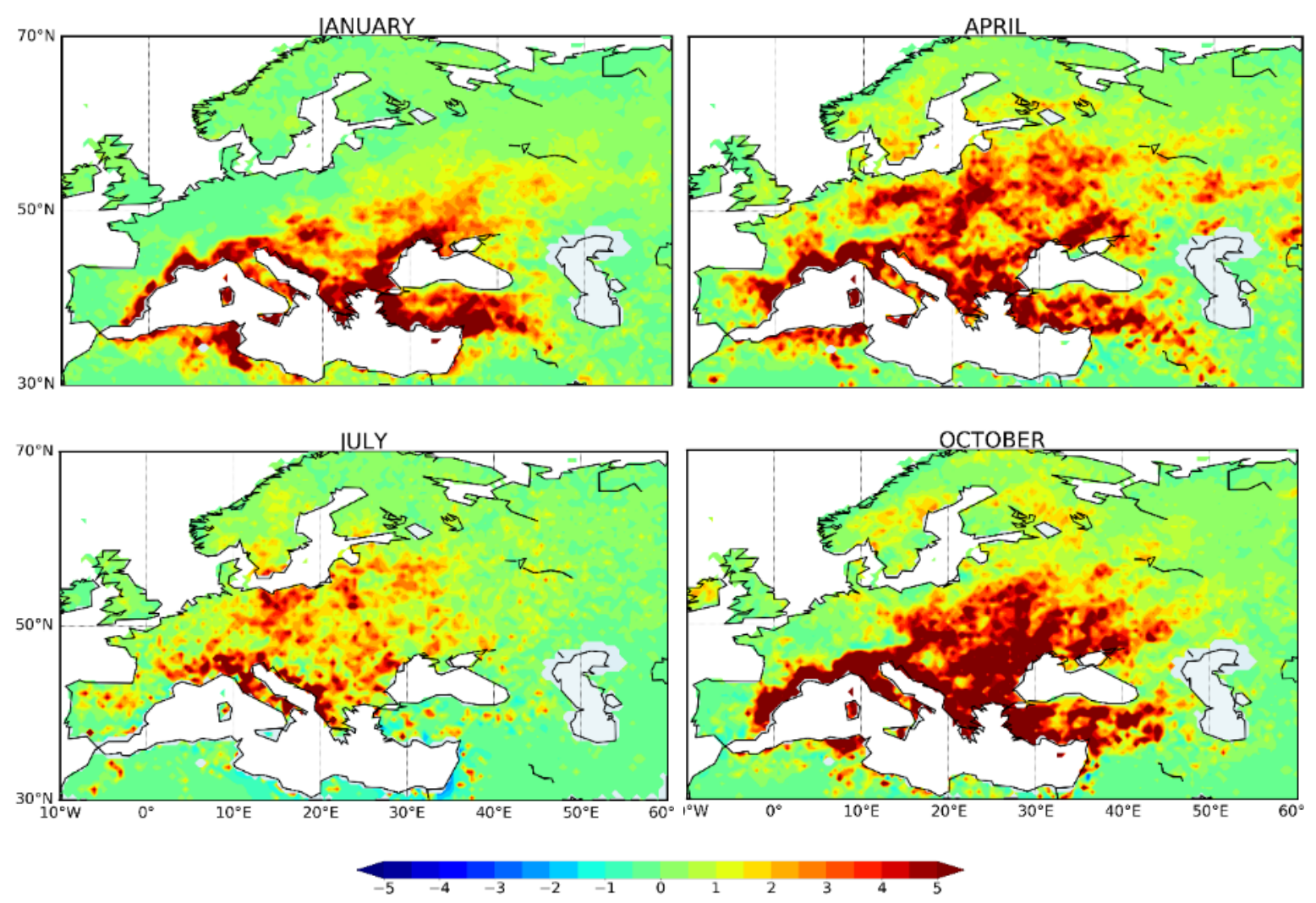

Figure 2. Anomaly on the moisture contribution from the Mediterranean region for extreme precipitation events. Units in $\mathrm{mm} /$ day

In general terms, the moisture contribution from this source increases in association with extreme precipitation events, being the increase higher over the Mediterranean coastal areas where 
values may surpass the $5 \mathrm{~mm}$.day- 1 in some locations. Despite the general increase the patterns vary by season. In January the moisture contribution increase is located mainly over the coastal areas, while in the remaining seasons the increase occurs over further regions. In spring (April) and autumn (October) the contribution from the Mediterranean Sea shows higher values over eastern Europe (see also Figure S2 in Supplementary Materials). However, in autumn the area of maximum increase is more confined over southern areas. Finally, in summer the moisture contribution shows the lowest increase associated to extreme events, being in this case the area of higher contribution mainly located over eastern and South-Centre Europe.

In the case of the Atlantic source, the anomaly for extreme events associated with this source is presented in Figure 3 for January, April, July and October; while remaining months are presented in Figure S3. In this case, the contribution form the sources mainly increase over the western Iberian Peninsula in all the seasons associated with extreme precipitation events. Central Europe also shows a general increase in the moisture contribution, being the magnitude lower than over Iberian Peninsula. As for Mediterranean Source, the lowest increase occurs in Summer. In this season the moisture contribution is more homogeneously distributed over western Europe. In autumn important increases can be observed over most of the southern European coast, a region where the Mediterranean contribution especially relevant.
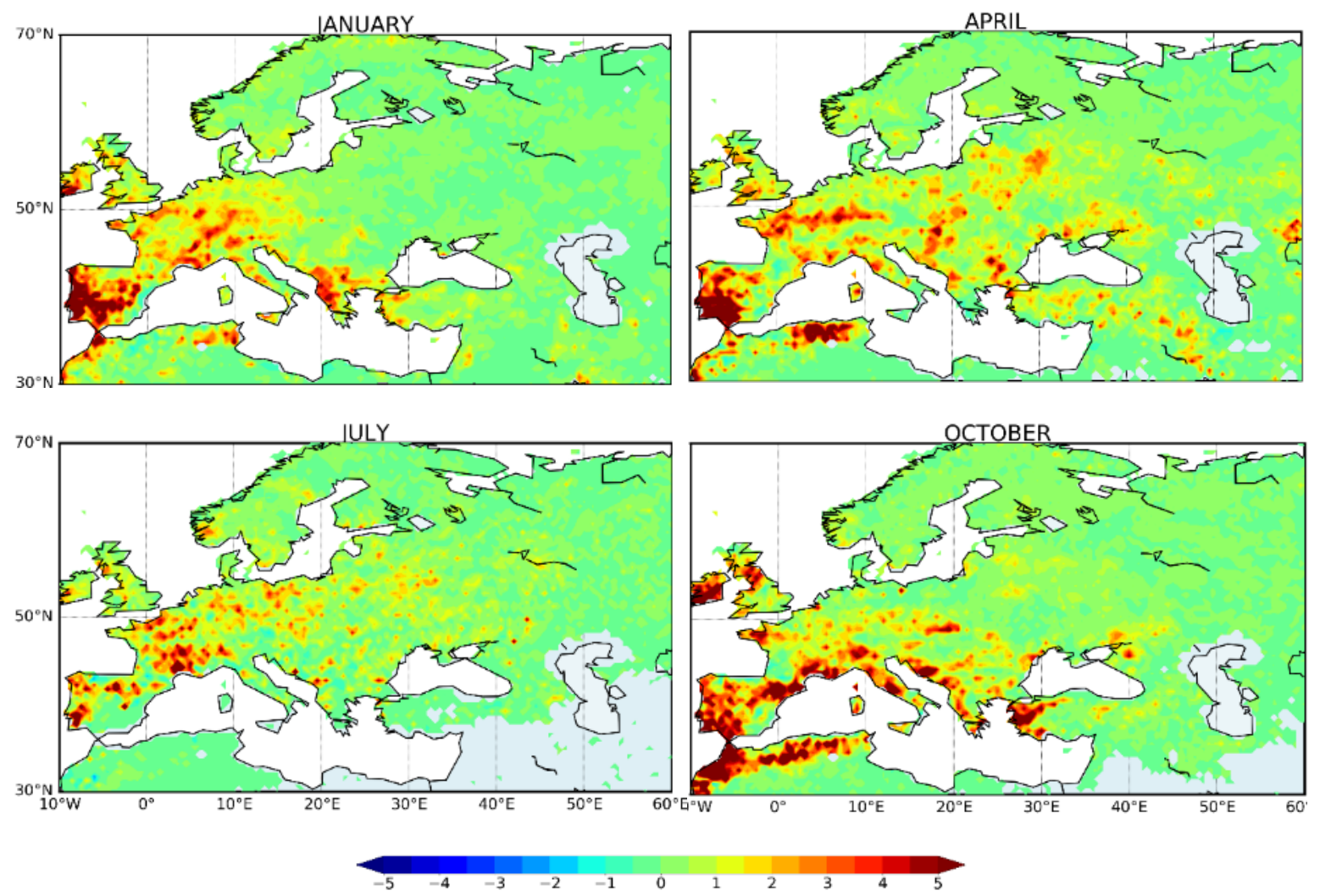

Figure 3. Anomaly on the moisture contribution (in mm/day) from the North Atlantic for extreme precipitation events.

On Figure 2 and Figure 3, the variation in the moisture contribution associated with extreme events is investigated. However, it is also of interest to compare the moisture contribution from both sources. When directly comparing the moisture contribution from both sources (Figure 2 and Figure 3) it can be observed that the increase in the moisture contribution associated with extreme events is higher for the Mediterranean Sea. However, to investigate which source contributes more to precipitation could result of interest and is discussed below. 
The 3rd International Electronic Conference on Atmospheric Sciences (ECAS 2020), 16-30 November 2020;

Sciforum Electronic Conference Series, Vol. 3, 2020

\subsection{Main moisture source variation}

For this purpose, the Figure 4 represents over every grid point the source showing the higher contribution. This result is presented for both, the mean climatological contribution and the extreme precipitation events composite. As expected, the North Atlantic source is dominant over north western Europe, while the Mediterranean is the main source in the south-eastern part of the continent. Despite this general pattern, some variation can be observed between the climatology and extreme precipitation situation.

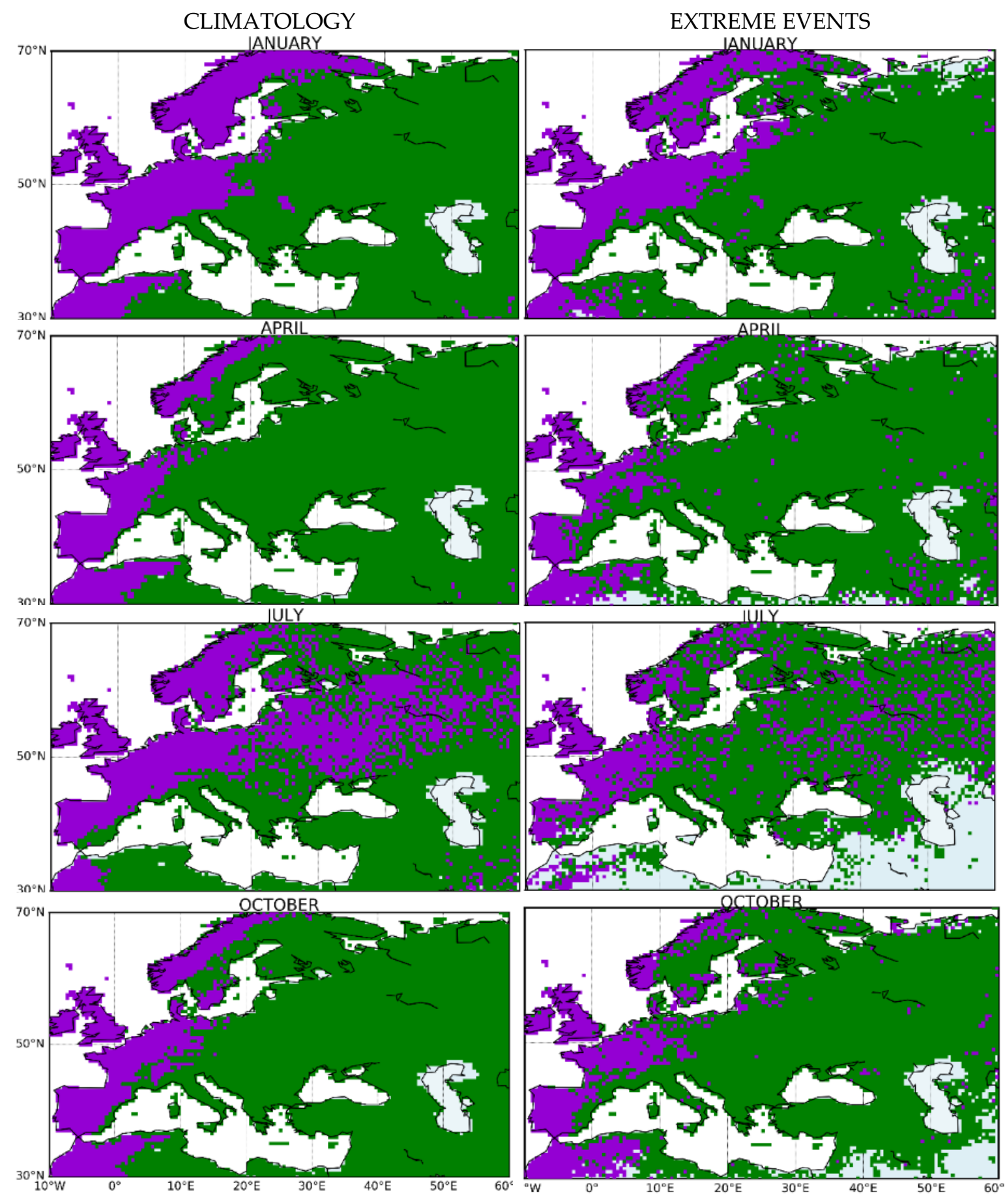


Figure 4. Dominant moisture source over Europe for climatology (left column) and extreme precipitation events (right column). Purple color represents those areas with higher contribution from the NATL source while greener areas represent the MED area of higher influence.

In January, the moisture contribution form the NATL seems to further penetrate into the continent over northern areas associated with extreme events. However, the MED source expands its influence over the eastern Iberian Peninsula. In April and October not important variations on the sources' distribution are observed. Finally, in July, the NATL area of maximum influence is reduced being limited to the western area. It is important to notice the different patterns observed in Winter and Summer. While in the former season the NATL region seems to penetrate into Central Europe, in the later its effect appears reduced over most of eastern Europe.

\section{Conclusions}

In this work the moisture contribution from the North Atlantic (NATL) and Mediterranean (MED) moisture sources associated with extreme precipitation events is investigated. Both sources show a general increase in the moisture contribution for extreme precipitation days over most of Europe. The increase is higher for Mediterranean source and show the lowest value in summer associated with both sources. The area of higher influence associated with the sources shows a redistribution in summer and winter. The North Atlantic penetrates further into Europe in winter while its area of influence is reduced in summer. Further investigation needs to be performed in order to analyze the causes of this redistribution.

Supplementary Materials: The following are available online at www.mdpi.com/xxx/s1, Figure S1: NATL source monthly variation, Figure S2: MED moisture contribution anomaly, Figure S3: NATL moisture contribution anomaly.

Author Contributions Conceptualization, M.V., R.N. and L.G.; methodology, M.V. and F.F.; formal analysis, M.V., M.L. and F.F.; investigation, X.X.; writing-original draft preparation, M.V..; writing-review and editing, M.L..; visualization, M.V. and F.F.; supervision, L.G., R.N. and M.L.; funding acquisition, R.N., M.L. and L.G. All authors have read and agreed to the published version of the manuscript

Funding: Marta Vazquez is supported by the Xunta de Galicia under grant ED481B 2018/062. This work is supported by Fundação para a Ciência e a Tecnologia - FCT and Portugal Horizon2020 through project "Weather Extremes in the Euro Atlantic Region: Assessment and Impacts - WEx-Atlantic" (PTDC/CTA-MET/29233/2017). This work was partially supported by Xunta de Galicia under Project ED431C 2017/64-GRC "Programa de Consolidación e Estructuración de Unidades de Investigación Competitivas (Grupos de Referencia Competitiva)". The work forms part of the LAGRIMA project.

Conflicts of Interest: The authors declare no conflict of interest

\section{References}

1. Trenberth, K.E. Changes in precipitation with climate change. Clim. Res. 2011, 47. https://www.intres.com/abstracts/cr/v47/n1-2/p123-138.

2. Papalexiou, S. M., \& Montanari, A. Global and regional increase of precipitation extremes under global warming. Water Resources Research 2019, 55, 4901- 4914. https://doi.org/10.1029/2018WR024067

3. Donat, M., Lowry, A., Alexander, L. et al. More extreme precipitation in the world's dry and wet regions. Nature Clim Change 2016, 6, 508-513. https://doi.org/10.1038/nclimate2941.

4. Myhre, G., Alterskjær, K., Stjern, C.W. et al. Frequency of extreme precipitation increases extensively with event rareness under global warming. Sci. Rep. 2019, 9, 16063. https://doi.org/10.1038/s41598-019-52277-4

5. Skliris, N., Zika, J.D., Herold, L. et al. Mediterranean sea water budget long-term trend inferred from salinity observations. Clim. Dyn. 2018, 51, 2857-2876. https://doi.org/10.1007/s00382-017-4053-7.

6. Craig, P.M., Ferreira, D. and Methven, J. The contrast between Atlantic and Pacific surface water fluxes, Tellus A: Dynamic Meteorology and Oceanography 2018, 69:1, https://doi.org/10.1080/16000870.2017.1330454. 
The 3rd International Electronic Conference on Atmospheric Sciences (ECAS 2020), 16-30 November 2020;

Sciforum Electronic Conference Series, Vol. 3, 2020

7. Volosciuk, C., Maraun, D., Semenov, V. et al. Rising Mediterranean Sea Surface Temperatures Amplify Extreme Summer Precipitation in Central Europe. Sci Rep. 2016, 6, 32450 . https://doi.org/10.1038/srep32450

8. Lavers, D. A., and Villarini, G. The nexus between atmospheric rivers and extreme precipitation across Europe, Geophys. Res. Lett. 2013, 40, 3259-3264, doi:10.1002/grl.50636.

9. Hofstätter, M., Lexer, A., Homann, M. and Blöschl, G. Large-scale heavy precipitation over central Europe and the role of atmospheric cyclone track types. Int. J. Climatol. 2018 38: e497-e517. doi:10.1002/joc.5386

10. Kunkel, K.E., D.R. Easterling, D.A. Kristovich, B. Gleason, L. Stoecker, and R. Smith. Meteorological Causes of the Secular Variations in Observed Extreme Precipitation Events for the Conterminous United States. J. Hydrometeor. 2012, 13, 1131-1141, https://doi.org/10.1175/JHM-D-11-0108.1

11. Nieto, R. Ciric, D., Vázquez, M., Liberato, M.L.R. and Gimeno, L. Contribution of the main moisture sources to precipitation during extreme peak precipitation months, Advances in Water Resources 2019, , 131, 1-8. https://doi.org/10.1016/j.advwatres.2019.103385

12. Stohl A., Hittenberger M., Wotawa G. Validation of the Lagrangian particle dispersion model FLEXPART against large scale tracer experiments. Atmos. Environ. 1998, 32, 4245-4264. https://doi.org/10.1016/S13522310(98)00184-8

13. Stohl A., Forster C., Frank A., Seibert P., Wotawa G.. Technical note: The Lagrangian particle dispersion model FLEXPART version 6.2. Atmos. Chem. Phys. 2005, 5, 2461-2474. https://doi.org/10.5194/acp-52461-2005.

14. Stohl A., Thomson D. J. . A density correction for Lagrangian particle dispersion models. Bound.-Layer Met. 1999 90, 155-167. https://doi.org/10.1023/A:1001741110696

15. Pisso I., Sollum E., Grythe H., Kristiansen N., Cassiani M., Eckhardt S., Arnold D., Morton D., Thompson R.L., Zwaaftink C.D.G., Evangeliou N., Sodemann H., Haimberger L., Henne S., Brunner D., Burkhart J.F., Fouilloux A., Brioude J., Philipp A,M Seibert P., Stohl A.. The Lagrangian Particle Dispersion Model FLEXPART Version 10.3. Geoscientific Model Development Discussions 2019, 1-67. https://doi.org/10.5194/gmd-2018-333.

16. Stohl A., James P.A. A Lagrangian Analysis of the Atmospheric Branch of the GlobalWater Cycle. Part I: Method Description, Validation, and Demonstration for the August 2002 Flooding in Central Europe. J. Hydrometeorol. 2004, 5, 656-678. https://doi.org/10.1175/1525-7541(2004)005<0656:ALAOTA>2.0.CO;2

17. Stohl A. James P.A. A Lagrangian Analysis of the Atmospheric Branch of the GlobalWater Cycle. Part II: Moisture Transports between Earth's Ocean Basins and River Catchments. J. Hydrometeorol. 2005, 6, 961984. https://doi.org/10.1175/JHM470.1

18. Nieto R., Gimeno L. A database of optimal integration times for Lagrangian studies of atmospheric moisture sources and sinks. Scientific Data 2019, 6, 1-10. https://doi.org/10.1038/s41597-019-0068-8 (C) 2020 by the authors. Submitted for possible open access publication under the terms and conditions of the Creative Commons Attribution (CC BY) license (http://creativecommons.org/licenses/by/4.0/). 